\title{
One-year prospective registry of inflammatory bowel disease in the Argentine pediatric population
}

\author{
Rosalia Vicentín, M.D. ${ }^{a}$, Marta Wagener, M.D. ${ }^{a}$, Alejandro B. Pais, M.D. ${ }^{a}$, \\ Mónica Contreras, M.D. ${ }^{b}$ and Marina Orsi, M.D. ${ }^{c}$
}

\begin{abstract}
Introduction. Inflammatory bowel disease (IBD) includes ulcerative colitis (UC) and Crohn's disease (CD). IBD diagnosis has become increasingly common in pediatrics but its incidence is unknown in Argentina. The objective of this study was to determine the annual incidence of IBD in children and adolescents younger than 18 years in Argentina, its epidemiological aspects, and clinical presentations.
\end{abstract}

Population and methods. Prospective, observational, multicenter study conducted in Argentina. Children and adolescents younger than 18 years from public and private facilities, diagnosed with IBD between June 1 $1^{\text {st }}, 2012$ and May $31^{\text {st }}, 2013$ were included via a web protocol. Results. Seventeen sites participated in the study; 50 patients were recruited from 10 sites. IBD incidence was $0.4 / 100000$ among individuals $<18$ years; CD, 20; UC, 25; and idiopathic IBD, 5 . Distribution by sex: 26 boys and 24 girls. Patients' mean age at diagnosis was 9.7 years, and delay in the diagnosis was 16.5 months. The most common symptoms and signs were chronic diarrhea with blood and/or mucus, abdominal pain, and weight loss. Growth retardation was less common than expected. Extraintestinal manifestations were observed in $24 \%$ of UC cases and in $25 \%$ of CD cases. The most common location of $\mathrm{CD}$ was the ileum and colon, and of $\mathrm{UC}$ was the entire colon (pancolonic). There were no cases with severe UC.

Conclusions. The incidence was lower than that reported in other registries. We recommend the development of an ongoing registry, to establish the incidence of IBD, but also to serve as backup for referring facilities where this disease is diagnosed and treated.

Key words: Inflammatory bowel disease, ulcerative colitis, Crohn's disease, prospective registry.

\section{E-mail address:}

Rosalía Vicentín, M.D.:

vicentinrosalia@gmail.com

\section{Funding:}

Research fellowship granted by the

Argentine Society

of Pediatrics and

Fundación Más Vida.

Conflict of interest:

None.

Received: 8-17-2016

Accepted: 4-26-2017

\section{Collaborators:} del Litoral.

Participating sites and collaborators: See Annex

\section{INTRODUCTION}

Inflammatory bowel disease (IBD) includes ulcerative colitis (UC) and Crohn's disease (CD). It also includes a third category called idiopathic inflammatory bowel disease (IIBD). Diagnostic criteria are based on the Porto criteria, which include clinical, radiological, endoscopic, and histological features. ${ }^{1-3}$

Although the definite etiology of this disease is unknown, genetic and environmental risk and protective factors have been identified in association with it. ${ }^{4}$

Most data on its incidence and prevalence are obtained from publications made abroad and very few data are available in Latin America.

The incidence of $\mathrm{CD}$ has increased progressively whereas that of UC has remained stable according to different prospective registries from Canada and the United Kingdom. The annual incidence of $C D$ ranges between 2.3 and 8.4 per 100000 children and adolescents younger than 18 years, and of UC, between 1.9 and 3.2.5.14

IBD prevalence has been reported to range between 41 and 79 cases per 100000 in the United States and Northern Europe.

The objective of this study was to determine the annual incidence of IBD in children and adolescents younger than 18 years in Argentina, epidemiological aspects, and clinical presentations.

Emiliano Chaves, B.S., Elena Fernández de Carrera, B.S.

Department of Math of the School of Biochemistry and Biological Sciences. Universidad Nacional 


\section{MATERIAL AND METHOD}

This was a prospective, observational, multicenter, and national study that recruited all newly diagnosed IBD cases between June $1^{\text {st }}, 2012$ and May 31 ${ }^{\text {st }}, 2013$.

Health care providers from different Argentine sites were invited to take part in the study through the national network of pediatric gastroenterologists (NotiGastro).

Those health care providers who did not have an Internet connection at their workplace were offered a Word format form; they were asked to complete it and send it to be entered online.

Patients younger than 18 years were included in the study; pre-established data were reported in a protocol and included clinical presentation, epidemiological aspects, radiology testing and/ or endoscopic and anatomopathological features.

The following outcome measures were assessed:

\section{Clinical data}

Sex, age at diagnosis, time elapsed since the first symptoms until diagnosis, and clinical manifestations: abdominal pain, diarrhea, bloody stools, tenesmus and rectal strain, perianal disease, weight loss, anorexia, growth retardation, and delayed puberty.

Extraintestinal manifestations: arthritis, erythema nodosum, pyoderma gangrenosum, oral sores, autoimmune hepatitis, and sclerosing cholangitis. ${ }^{15-19}$
Protective and risk factors associated with IBD development: socioeconomic level, personal and family medical history of autoimmune conditions, smoking, immunization, breastfeeding, appendectomy, emotional distress, and history of major bacterial or viral infections., ${ }^{415}$

\section{Laboratory data}

Hematocrit and hemoglobin, erythrocyte sedimentation rate (ESR), white blood cell count, anti-Saccharomyces cerevisiae antibodies (ASCAs), anti-neutrophil cytoplasmic antibodies (ANCAs), gamma globulin, platelet count, albumin level.

\section{Supplementary tests}

Upper GI series, small bowel and colon series, upper videoendoscopy, and videocolonoscopy with ileal intubation, with details of the bowel segments assessed during endoscopy, type and characteristics of involvement observed. Pathology report.

Location, extent, and severity of disease based on the Montreal classification. ${ }^{20}$

The Truelove and Witts' severity index was used to assess the severity of UC and IIBD. ${ }^{21}$

\section{Statistical analysis}

The incidence was determined using ratios and the corresponding confidence intervals. The significance level was established at $\alpha=0.05$. It was determined based on the number of new cases reported over the total population of

TABLE 1. Participating sites and patients from each site (number and percentage)

\begin{tabular}{lcc}
\hline Participating sites & Selected patients & Percentage of patients (\%) \\
\hline Hospital Garrahan (Autonomous City of Buenos Aires) & 23 & 46 \\
Hospital Italiano (Autonomous City of Buenos Aires) & 9 & 18 \\
Sanatorio de Niños de Rosario (Rosario, Santa Fe) & 4 & 8 \\
Hospital Infantil Municipal (Córdoba) & 3 & 6 \\
Hospital de Niños Dr. R. Gutiérrez (Autonomous City of Buenos Aires) & 3 & 6 \\
Instituto del Niño (Rosario, Santa Fe) & 2 & 4 \\
Hospital Materno Infantil (San Isidro, Buenos Aires) & 2 & 4 \\
Hospital de Niños Víctor J. Vilela (Rosario, Santa Fe) & 4 \\
Hospital Sor María Ludovica (La Plata, Buenos Aires) & 2 & 2 \\
Hospital de Niños Dr. O. Alassia (Santa Fe) & 1 & 2 \\
Hospital Castelán (Resistencia, Chaco) & 1 & 0 \\
Hospital de Alta Complejidad Pte. J. D. Perón (Formosa) & 0 & 0 \\
Hospital de Niños Juan Pablo II (Corrientes) & 0 & 0 \\
Hospital Regional (Ushuaia, Tierra de Fuego) & 0 & 0 \\
Hospital Universitario Austral (Pilar, Buenos Aires) & 0 & 0 \\
Hospital Público Materno Infantil (Salta) & 0 & 0 \\
Hospital General de Agudos Dr. I. Pirovano (Autonomous City of Buenos Aires) & 0 & 100 \\
Total & 50 & 0 \\
\hline
\end{tabular}


individuals by age, obtained from the National Population Census of 2010 from the National Statistics and Censuses Institute of Argentina (Instituto Nacional de Estadísticas y Censos, INDEC) database. ${ }^{22}$

For data processing, the following software was used: Epi Info 2000, SPSS for Windows 2006, and Microsoft Office 2000.

\section{RESULTS}

Seventeen sites were included nationwide; 10 recruited patients and the other 7 replied that no new patients had been admitted to be included in the study. Table 1 shows participating sites and the number of patients contributed by each site.

Fifty patients were included in the registry; $35(70 \%)$ of them were referred from hospitals in the Autonomous City of Buenos Aires; of these, only $13(37 \%)$ resided in the city itself.

Table 2 shows new cases by origin of the patient and the provincial incidence (total population by age range as per the INDEC). The highest incidence was observed in the Autonomous City of Buenos Aires (2.4/100 000) and Santa Fe (1.0/100 000); the total incidence for Argentina was 0.4/100 000 inhabitants younger than 18 years.

\section{Sex and age at diagnosis:}

Twenty-four girls and 26 boys were included; their mean age at diagnosis was 9.7 years among CD patients, 9.4 years among UC patients, and 10.8 years among those with IIBD. The youngest age at diagnosis was 2 years and 6 months whereas the oldest was 17.9 years, both in the UC group.

\section{Diagnosis:}

Based on the pathology report, 20 patients were diagnosed with $\mathrm{UC}, 20$ had $\mathrm{CD}$, and 10 had IIBD; among the latter, 5 patients were clinically classified as having UC.

The average time between the onset of symptoms and the diagnosis was 16.5 months; the longest time was 60 months in a patient with CD.

Symptoms, signs, and extraintestinal manifestations according to definite diagnosis:

Out of the 20 patients diagnosed with CD, 18 had chronic diarrhea; 17 , chronic abdominal pain; 16, stools with blood and mucus; 15 , weight loss; and 2, perianal disease. In terms of extraintestinal manifestations, 4 patients had arthritis and 1, erythema nodosum. None of the patients with $\mathrm{CD}$ had liver disease.

Among the 25 patients with UC, 23 had diarrhea; 24, bloody stools; 17, mucus in stools; 19 , chronic abdominal pain; and 15, weight loss. In terms of extraintestinal manifestations, 5 patients had autoimmune liver disease ( 3 corresponded to autoimmune hepatitis and 2 to sclerosing cholangitis) and 1 had arthritis.

Only 6 patients (12\%) (4 with CD and 2 with $\mathrm{UC})$ had growth retardation.

Out of the 5 patients with IIBD, all had diarrhea with blood; 3 , one or more of the following symptoms: oral sores, anorexia, weight loss, or chronic abdominal pain; and 2 had autoimmune hepatitis (Tables 3 and 4 ).

\section{Socioeconomic aspects:}

Ninety-eight percent of patients had access to drinking water and $90 \%$ had excreta-disposal facilities connected to the sewer system.

TABLE 2. New inflammatory bowel disease cases diagnosed in the 2012-2013 period per 100000 children and adolescents younger than 18 years, by province and total for Argentina

\begin{tabular}{lccc}
\hline Province & Total population & Patients diagnosed with IBD & Per 100 000 inhabitants younger than 18 years \\
\hline Buenos Aires & 4399832 & 14 & 0.3 \\
CABA & 531246 & 13 & 2.4 \\
Chaco & 374159 & 1 & 0.3 \\
Córdoba & 924637 & 3 & 0.3 \\
Corrientes & 338947 & 2 & 0.6 \\
Entre Ríos & 374316 & 3 & 0.8 \\
Mendoza & 509960 & 1 & 0.2 \\
Misiones & 408611 & 1 & 0.2 \\
San Juan & 221489 & 2 & 0.9 \\
Santa Fe & 862475 & 9 & 1.0 \\
Tucumán & 468262 & 1 & 0.2 \\
Argentina & 11691156 & 50 & 0.4 \\
\hline
\end{tabular}

IBD: inflammatory bowel disease; CABA: Autonomous City of Buenos Aires. 
All school-age patients attended school, and $90 \%$ of parents had completed secondary or higher education.

\section{Medical history among first-degree relatives:}

Out of 50 patients, 27 had no medical history and 13 were unaware of it. Ten out of 50 patients referred their family history included autoimmune thyroiditis (3), depression, celiac disease, immune blood disorder, skin allergy, autoimmune diabetes, and collagen disease.

Medical history among second-degree relatives:

Out of 50 patients, 25 had no medical history and 17 were unaware of it. Eight out of 50 patients referred IBD (2), colon cancer, prostate cancer, celiac disease, autoimmune diabetes, and thyroiditis.

In total, 13 patients $(26 \%)$ had first- and second-degree relatives with a history of autoimmune conditions.
Medical history probably associated with IBD:

- Appendectomy in 1 patient with CD.

- Major infections in 6 patients.

- BCG and measles vaccination in all patients.

- Exclusive breastfeeding up to 6 months in half of the patients.

- Passive smoking in $11 / 50$ patients at home and no active smoking.

- Emotional distress: 10/50 patients reported emotional distress at disease onset; of these, 7 had UC.

\section{Lab tests}

Hematocrit lab test results were mostly above $30 \%$; results were lower among patients diagnosed with UC.

Hemoglobin values were below 9.5 in 11 out of 50 patients; 7 of these patients had UC. In addition, the lowest hemoglobin values were also observed in patients with UC.

TABLE 3. Symptoms and signs based on diagnosis

\begin{tabular}{lccc}
\hline Symptoms and signs & \multicolumn{1}{c}{ Patient diagnosis } & CD (n: 20) \\
\cline { 2 - 4 } & IIBD (n: 5) & UC (n: 25) & 18 \\
Diarrhea & 5 & 23 & 16 \\
Mocus & 3 & 17 & 1 \\
Pus & 0 & 0 & 16 \\
Blood & 5 & 24 & 11 \\
Rectal strain and/or tenesmus & 3 & 10 & 0 \\
Rectal prolapse & 0 & 0 & 17 \\
Chronic abdominal pain & 4 & 19 & 2 \\
Persistent fever & 0 & 0 & 0 \\
Delayed puberty & 0 & 1 & 6 \\
Oral sores & 3 & 2 & 8 \\
Anorexia & 2 & 10 & 0 \\
Toxic megacolon & 0 & 0 & 4 \\
Weight loss & 2 & 15 & 2 \\
Height and weight growth retardation & 0 & 2 & 4 \\
Perianal disease & 0 & 0 & 2 \\
\hline
\end{tabular}

n: total number; IIBD: idiopathic inflammatory bowel disease; UC: ulcerative colitis; CD: Crohn's disease.

TABLE 4. Extraintestinal manifestations based on diagnosis

\begin{tabular}{lccc}
\hline Extraintestinal manifestations & \multicolumn{1}{c}{ Patient diagnosis } \\
\cline { 2 - 4 } & IIBD (n: 5) & UC (n: 25) & CD (n: 20) \\
Pyoderma & 0 & 0 & 0 \\
Erythema nodosum & 0 & 0 & 1 \\
Arthritis & 0 & 1 & 0 \\
Liver disease & 2 & 3 & 0 \\
$\quad$ Autoimmune hepatitis & 0 & 2 & 0 \\
$\quad$ Sclerosing cholangitis & & & \\
\hline
\end{tabular}

n: total number; IIBD: idiopathic inflammatory bowel disease; UC: ulcerative colitis; CD: Crohn's disease. 
The highest platelet count values (725 000) and ESR (120) corresponded to patients with CD. The difference in medians for ESR and platelet count relative to the diagnosis of disease was established using an analysis of variance (ANOVA). The difference was significant for platelet count ( $p=0.028$ ) (Figure 1). In relation to albumin, the $p$ value was significant at 0.025 .

Anti-Saccharomyces cerevisiae antibodies (ASCAs) and perinuclear anti-neutrophil cytoplasmic antibodies ( $p$-ANCAs).

ASCAs and p-ANCAs were obtained only in 27 patients $(54 \%)$.

\section{Severity of the disease:}

Based on the Truelove and Witts' severity index, 24 patients with UC $(96 \%)$ had mild to moderate disease and only 1 had the severe form whereas $100 \%$ of patients with IIBD had inactive or mild disease (Table 5).

\section{Extent of the disease:}

IIBD: 4 in the entire colon and 1 in the left colon.

UC: 19 in the entire colon, 4 in the left colon, and 2 in the rectum.

CD: 16 in the ileum and colon, 3 in the colon and 1 in the rectum and colon.

\section{Endoscopy}

An upper endoscopy was done in 47 patients (94\%); it reached the duodenum in all patients.

A colonoscopy was done in the 50 patients $(100 \%)$; it reached the ileum in $32(64 \%)$ and the right colon in 15 (30\%).

All patients with CD underwent an upper

FIGURE 1. Box plot for platelet count based on the diagnosis of inflammatory bowel disease showing median and interquartile range values

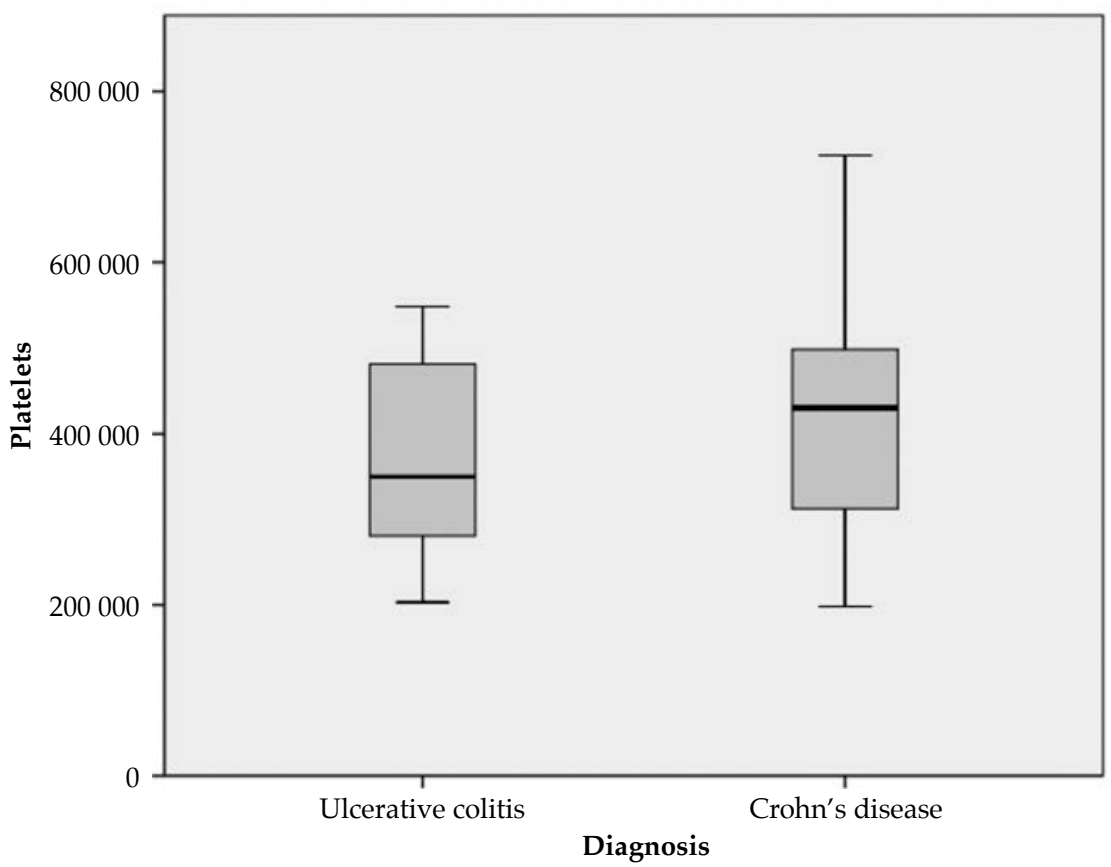

TABle 5. Patient diagnosis and severity of the disease

\begin{tabular}{llccccc}
\hline & \multicolumn{3}{c}{ Severity } \\
\cline { 2 - 6 } & & Inactive & Mild & Moderate & Severe & Total \\
\hline Patient diagnosis & IIBD & 2 & 3 & 0 & 0 & 5 \\
& UC & 0 & 16 & 8 & 1 & 25 \\
\hline
\end{tabular}

IIBD: idiopathic inflammatory bowel disease; UC: ulcerative colitis. 
endoscopy and a colonoscopy; the terminal ileum could not be reached in 3 of them.

\section{Radiology}

A small bowel series was done in 19 cases (38\%); 4 (21\%) showed pathological findings.

\section{DISCUSSION}

This study reported an annual incidence of IBD of $0.4 / 100000$ children and adolescents younger than 18 years, which was surprisingly lower than what has been observed in other registries (United Kingdom: 5/100 000 per year; Slovenia: 7.6/100 000), and showed geographic dissimilarities across Argentina. ${ }^{7-26}$

The incidence in the Autonomous City of Buenos Aires was 2.4/100 000, closest to other reports, whereas a very low incidence was reported in the province of Buenos Aires, even lower than in other provinces. In Greater Buenos Aires, which comprises 24 districts, the same number of patients was registered in the same period as in the Autonomous City of Buenos Aires; however, the rate was low $(0.4 / 100000)$ due to the population size. The incidence observed in the provinces of Santa Fe, San Juan and Entre Ríos was similar (1.0, 0.9 and $0.8 / 100000$, respectively).

The incidence reported in the Autonomous City of Buenos Aires corresponded to a half of that observed in the reference countries. The difference from other provinces may be the result of several factors: 1) a higher rate of suspicion and diagnostic accuracy in tertiary care facilities; 2) a higher incidence in locations with increased urbanization and population density; and 3) probable impact of socioeconomic, racial, cultural, and geographic aspects.

Unlike the greatest prevalence of $\mathrm{CD}$ reported in other registries, in our study, UC-IIBD accounted for $60 \%$ of cases and CD, for $40 \% .^{5-14}$

Sex distribution was similar, contrary to most publications that have described a higher frequency of $\mathrm{CD}$ among males. The average age at diagnosis was 9.7 years and was consistent with that reported in the bibliography. ${ }^{5-16}$

The distribution by patient age at diagnosis was consistent across the different pediatric series. ${ }^{10-14}$

Although this is a chronic disease with frequent relapses, the rate of school attendance was high; this leads to assuming that IBD may have a low general involvement or that families and/or health care teams provide a great level of support.
In terms of socioeconomic status, $98 \%$ of patients had running water and $90 \%$ had a sewer system; this was consistent with the bibliography worldwide, and allowed to establish that IBD was more common in the populations with better sanitary conditions. ${ }^{2,4}$

Certain known risk factors for the development of IBD were also studied, such as lack of breastfeeding, passive smoker status, and emotional distress. However, in our study, no association with these risk factors was established.

It is important to consider that data collected are usually compared to those of registries from developed countries, and this is a limitation hard to overcome to make conclusions due to ethnic, financial, cultural, and environmental differences among the various populations..$^{3-15}$

Family medical history was recorded in $36 \%$ of patients; $26 \%$ had a history of autoimmune conditions.

The most common symptoms and signs observed in patients with CD and UC were chronic diarrhea and chronic abdominal pain, stools with blood and mucus, and weight loss; all were consistent with the bibliography. However, although an attempt was made to correlate symptoms and signs to the clinical presentations of IBD, it was not possible to make conclusions probably due to the frequent colon involvement in our patients with $\mathrm{CD}$, which tended to modify typical symptoms of this disease.

Only $12 \%$ of patients (4 with CD and 2 with $\mathrm{UC}$ ) had growth retardation; this percentage was lower to that described in the bibliography (between $25 \%$ and $42 \%$, where CD patients accounted for the higher percentage). ${ }^{2}$

The percentage of extraintestinal manifestations at diagnosis was similar to that reported in international studies. ${ }^{18,19}$

Lab tests showed significantly higher platelet counts and significantly lower albumin levels among patients with CD compared to those with UC. It was not possible to make conclusions in terms of ASCAs and p-ANCAs due to the low number of determinations made across the different departments and hospitals of Argentina.

In relation to diagnostic procedures, most patients were studied in full with an upper endoscopy and a colonoscopy, as proposed by the guidelines and consensuses for IBD. In our series, $100 \%$ of patients with CD and $87 \%$ of those with UC underwent both procedures. It was not possible to reach the ileum only in $10 \%$ of cases with $C D$. These findings were consistent with 
those published in the EUROKID registry from 2012. ${ }^{1,23-25}$

The small bowel series, a radiology test available in almost all facilities of Argentina, was performed in $40 \%$ of patients; this rate is much lower than what is recommended by the Porto criteria. ${ }^{1}$

In relation to the extent and severity of UC, it affected the entire colon of most patients, and it was mild in $70 \%$ and moderate in $26 \%$. Also, $40 \%$ of IIBD cases were inactive and $60 \%$, mild.

Since there are no other data on incidence available in Argentina and Latin America, and considering clinical differences in our patients compared to those of the bibliography, ${ }^{26,27}$ we propose the creation of an ongoing registry at a national level to reinforce these findings.

\section{CONCLUSIONS}

The estimated incidence of IBD based on this registry was lower than that reported in recent studies conducted in developed countries. No differences were observed in sex distribution between UC and CD patients. Mean age at diagnosis was consistent with that reported in other registries. The classical triad of diarrhea with mucus and/or blood, abdominal pain, and weight loss was the most common presentation for both UC and CD. Growth retardation was less common than expected. The clinical presentations of UC were mild and moderate; no severe forms were observed. It is necessary to develop an ongoing, coordinated registry at a national level.

\section{REFERENCES}

1. IBD Working Group of the European Society of Pediatric Gastroenterology, Hepatology and Nutrition. Inflammatory bowel disease in children and adolescents: recommendations for diagnosis-the Porto criteria. J Pediatr Gastroenterol Nutr 2005;41(1):1-7.

2. Wyllie R.Jeffrey H.MarshaK(eds).Pediatric Gastrointestinal and Liver Disease. 4th ed. Philadelphia: Elsevier - Saunders, 2011.

3. Acuña Quirós MD, Alonso Franch M, Álvarez Coca J, et al. Protocolos diagnósticos y terapéuticos de Gastroenterología Hepatología y Nutrición Pediátrica SEGHNP-AEP. Madrid: Ergon, 2010. [Accessed on: April 27th 2017]. Available at: https: / / www.gastroinf.es/sites/default/ files / files / Protocolos\%20SEGHNP.pdf.

4. Kugathasan S, Amre D. Inflammatory bowel disease Environmental modification and genetic determinants. Pediatr Clin North Am 2006;53(4):727-49.

5. Benchimol EI, Guttmann A, Griffiths AM, et al. Increasing incidence of paediatric inflammatory bowel disease in Ontario, Canada: evidence from health administrative data. Gut 2009;58(11):1490-7.
6. Su H, Gupta V, Dav AS, et al. Rising Incidence of Inflammatory BowelDisease in Canterbury, New Zealand. Inflamm Bowel Dis 2016;22(9):2238-44.

7. Sawczenko A, Sandhu BK, Logan RF, et al. Prospective survey of childhood inflammatory bowel disease in the British Isles. Lancet 2001;357(9262):1093-4.

8. Van Assche G, Dignass A, Pane J, et al. The second European evidence-based consensus on the diagnosis and management Crohn's disease: Definitions and diagnosis. J Crohns Colitis 2010;4(1):7-27.

9. Ishige $\mathrm{T}$, Tomomasa $\mathrm{T}$, Hatori $\mathrm{R}$, et al. Temporal trend of pediatricinflammatory bowel disease: Analysis of national registry data 2004-2013 in Japan. J Pediatr Gastroenterol Nutr 2017 [Epub ahead of print].

10. Molodecky NA, Soon IS, Rabi DM, etal.Increasing Incidence and Prevalence of the Inflammatory Bowel Diseases. Gastroenterology 2012;142(1):46-54.e42.

11. Martín-de-Carpi J, Rodríguez A, Ramos E, et al. Increasing incidence of pediatric inflammatory bowel disease in Spain (1996-2009): the SPIRIT Registry. Inflamm Bowel Dis 2013;19(1):73-80.

12. De Greef E, Mahachie John JM, Hoffman I, et al. Profile of pediatric Crohn's disease in Belgium. J Crohns Colitis 2013;7(11):e588-98.

13. Benchimol EI, Fortinsky KJ, Gozdyra P, etal. Epidemiology of pediatric inflammatory bowel disease: A systematic review of international trends. Inflamm Bowel Dis 2011;17(1):423-39.

14. Ludvigsson JF, Büsch $\mathrm{K}$, Olén $\mathrm{O}$, et al. Prevalence of paediatric inflammatory bowel disease in Sweden: A nationwide population-based register study. BMC Gastroenterol 2017;17(1):23.

15. Baldassano RN, Piccoli DA. Inflammatory bowel disease in pediatric and adolescent patients. Gastroenterol Clin N Am 1999;28(2):445-58.

16. Griffiths AM, Nguyen $P$, Smith C, et al. Growth and clinical course of children with Crohn's disease. Gut 1993; 34(7): 939-43.

17. Ballinger AB, Savage MO, Sanderson IR. Delayed puberty associated with inflammatory bowel disease. Pediatr Res 2003;53(2):205-10.

18. Danese S, Semeraro S, Papa A, et al. Extraintestinal manifestations in inflammatory bowel disease. World J Gastroenterol 2005;11(46):7227-36.

19. Jose FA, Heyman MB. Extraintestinal manifestations of inflammatory bowel disease. J Pediatr Gastroenterol Nutr 2008;46(2):124-33.

20. Van Limbergen J, Russell RK, Drummond HE, et al. Definition of phenotypic characteristics of childhoodonset inflammatory bowel disease. Gastroenterology 2008;135(4):1114-22.

21. Truelove SC, Witts LJ. Cortisone in ulcerative colitis; final report on a therapeutic trial. Br Med J 1955;2(4947):1041-8.

22. Instituto Nacional de Estadística y Censos- INDEC Argentina. Mapas temáticos Censo 2010. [Accessed on: August $1^{\text {st }}$,2015]. Available at: http:/ / www.sig.indec.gov. ar/censo2010/.

23. Sandhu BK, Fell JM, Beattie RM, et al. Guidelines for the management of inflammatory bowel disease in children in the United Kingdom. I Pediatr Gastroenterol Nutr 2010;50(Suppl 1):S1-13.

24. Turner D, Levine A, Escher JC, Griffiths AM, et al. Management of pediatric ulcerative colitis: joint ECCO and ESPGHAN evidence-based consensus guidelines. $J$ Pediatr Gastroenterol Nutr 2012;55(3):340-61. 
540 / Arch Argent Pediatr 2017;115(6):533-540 / Original article

25. Wilson DC, Thomas AG, Croft NM, et al.Systematic review of the evidence base for the medical treatment of paediatric inflammatory bowel disease. J Pediatr Gastroenterol Nutr 2010;50(Suppl 1):S14-34

26. UrlepD, Trop TK, Blagus R, et al. Incidence and phenotypic characteristics of pediatric IBD in northeastern Slovenia, 2002-2010. J Pediatr Gastroenterol Nutr 2014;58(3):325-32.

27. Ivković L, Hojsak I, Trbojević T, et al. The role of national registry in the care of children suffering from chronic inflammatory bowel disease. Paediatr Croat 2015;59(3):17380. 


\section{ANNEX \\ Participating sites and collaborators}

Hospital de Pediatría "Prof. Dr. Juan P. Garrahan," Autonomous City of Buenos Aires: Ruiz, José A.; Contreras, Mónica; Roca, Ana; Weyersberg, Cristian.

Hospital Italiano de Buenos Aires: Orsi, Marina; Gallo, Julieta.

Sanatorio de Niños, Rosario, Santa Fe: Costaguta, Alejandro; Tabacco, Omar.

Hospital Infantil Municipal, Córdoba: Marchisone, Silvia; Oropeza, Gabriela.

Hospital de Niños Dr. R. Gutiérrez, CABA: Aliboni, Vilma; Castagnino, Norma.

Instituto del Niño, Rosario, Santa Fe: Balbarrey, Silvina.

Hospital Materno Infantil de San Isidro, Buenos Aires: Mora, Mabel.

Hospital Dr. V. Vilela, Rosario, Santa Fe: Bordato, Juan; Bravo, Silvia.

Hospital Sor María Ludovica, La Plata, Buenos Aires: Ben, Ricardo; Uhlir, Anabela.

Hospital de Niños Dr. O. Alassia, Santa Fe: Wagener, Marta; Trotta, Liliana.

Hospital Castelán, Resistencia, Chaco: Martín, Graciela.

Hospital de Niños Juan Pablo II, Corrientes: Gudmman, Alejandro.

Hospital Regional de Ushuaia, Tierra de Fuego: Pastorizza, Néstor.

Hospital Universitario Austral, Pilar, Buenos Aires: Follet, Francisco.

Hospital Público Materno Infantil de Salta: Bastianelli, Cinthia.

Hospital General de Agudos Dr. I. Pirovano, CABA: Boggio Marzet, Christian.

Hospital de Alta Complejidad Pte. J. D. Perón, Formosa: Lazarte, Mario. 